\title{
As políticas públicas e as restaurações do Teatro Acció de San José de Mayo (Uruguai) e do Mercado Público de Jaguarão (Brasil). Um estudo comparativo de caso
}

\author{
Las políticas públicas y las restauraciones del Teatro Acció de San José de \\ Mayo (Uruguay) y del Mercado Público de Jaguarão (Brasil). Un estudio \\ comparativo de caso
}

\author{
The public policies and restorations of the Acció Theater of San José de \\ Mayo (Uruguay) and the Public Market of Jaguarão (Brazil). A \\ comparative case study
}

\author{
Carlos José Azevedo Azevedo Machado ${ }^{1}$
}

\begin{abstract}
Resumo
O presente artigo visa apresentar um estudo comparado do processo de restauração recente de dois espaços patrimoniais em duas cidades com histórias similares, uma no Uruguai e outra no Brasil, e sua relação com as Políticas Públicas para o Patrimônio. Teatro Bartolomé Macció, na cidade de San José de Mayo no Uruguai e o Mercado Público da cidade de Jaguarão no estado do Rio Grande do Sul, Brasil. Ambos os lugares fazem parte da memória dos moradores como um espaço de integração e encontros, que embora tenham sofrido ocupações diferentes, os levaram a sentirem-se pertencentes a estes lugares. Um voltado para as artes outro voltado para o comércio e lazer, mas ambos se relacionam, sobretudo nos dias de hoje, como lugares de memória e de história. San José de Mayo, fundada em 1783, inicialmente por "dragões" que foram acompanhados por 46 famílias e Jaguarão, fundada em 1801 por uma Guarda Militar onde em alguns anos torna-se uma importante freguesia por conta da população que acompanhou a Guarda e ali se estabeleceu. Ambas as cidades mantêm um acervo histórico arquitetônico invejável e guardam entre si muitas semelhanças, sobretudo pelo Ecletismo de suas construções.
\end{abstract}

Palavras-chave: Restauração, patrimônio, políticas públicas.

\section{Resumen}

El presente artículo pretende presentar un estudio comparado del proceso de restauración reciente de dos espacios patrimoniales en dos ciudades con historias similares, una en Uruguay y otra en Brasil, y su relación con las Políticas Públicas para el Patrimonio. Teatro Bartolomé Macció, en la ciudad de San José de Mayo en Uruguay y el Mercado Público de la ciudad de Jaguarão en el estado de Rio Grande do Sul, Brasil. Ambos lugares forman parte de la memoria de los moradores como un espacio de integración y encuentros, que aunque han sufrido ocupaciones diferentes, los llevaron a sentirse pertenecientes a estos lugares. Un volcado para las artes otro orientado hacia el comercio y el ocio, pero ambos se relacionan, sobre todo en los días de hoy, como lugares de memoria y de historia. San José de Mayo, fundada en 1783, inicialmente por "dragones" que fueron acompañados por 46 familias y Jaguarão, fundada en 1801 por una Guardia Militar donde en algunos años se convierte en una importante parroquia por cuenta de la población que acompañó a la Guardia y allí se estableció. Ambas ciudades mantienen un acervo histórico arquitectónico envidiable y guardan entre sí muchas semejanzas, sobre todo por el eclecticismo de sus construcciones.

\footnotetext{
${ }^{1}$ Mestre em Memória Social e Patrimônio Cultural; UFPEL; Pelotas; Brasil; cjmaninho@gmail.com
} 
Palabras clave: Restauración, patrimonio, políticas públicas.

\begin{abstract}
This article aims to present a comparative study of the process of recent restoration of two patrimonial spaces in two cities with similar histories, one in Uruguay and another in Brazil, and its relation with Public Policies for Patrimony. Teatro Bartolomé Macció in the city of San José de Mayo in Uruguay and the Public Market of the city of Jaguarão in the state of Rio Grande do Sul, Brazil. Both places are part of the memory of the residents as an area of integration and meetings, which although they have undergone different occupations, have led them to feel belonging to these places. One is geared towards the arts, and is geared towards commerce and leisure, but both are related, especially nowadays, as places of memory and history. San Jose de Mayo, founded in 1783, initially by "dragons" who were accompanied by 46 families and Jaguarão, founded in 1801 by a Military Guard where in a few years it became an important parish because of the population that accompanied the Guard and there if established. Both cities maintain an enviable architectural historical collection and keep among themselves many similarities, mainly by the eclecticism of their constructions.
\end{abstract}

Keywords: Restoration, patrimony, public policies.

\title{
1. Introdução
}

Estes espaços patrimoniais, Teatro Bartolomé Macció, na cidade de San José de Mayo no Uruguai e o Mercado Público Municipal de Jaguarão, no Brasil, sofreram recentemente um processo de restauração, onde o primeiro já foi entregue a comunidade em 13 de fevereiro de 2010 e o segundo iniciou suas obras no mês de agosto de 2014 e deverão ser concluídas no início de 2016. Estes lugares estavam sob proteção legal para sua preservação, conforme a legislação de cada país, fato que está diretamente relacionado às Políticas Públicas para o Patrimônio que foram mais fortemente desenvolvidas a partir da década de 1970, com a Convenção da UNESCO/ONU de 1972 para Salvaguarda do Patrimônio Material, tema que será abordado em título específico.

As duas cidades foram constituídas ao longo do século XIX e possuem uma história similar e mantém preservada boa parte de seu patrimônio edificado, sobretudo do final do século XIX às primeiras décadas do século XX e será apresentada de forma breve neste trabalho, o qual também faz parte da avaliação final da disciplina de Políticas Públicas de Memória e Patrimônio no Mercosul, segundo semestre de 2015, do curso de Pós Graduação em Memória Social e Patrimônio Cultural da Universidade Federal de Pelotas, a qual foi desenvolvida pelos professores Dra. Ana Maria Sosa Gonzáles e Dr. Ronaldo B. Colvero.

\section{As cidades}

San José de Mayo, no Uruguai, foi fundada em 1783, a partir do cumprimento de uma ordem de Virrey Vértiz, para ocupar e povoar a região. Chegaram às costas do arroio San José, e em $1^{\circ}$ de junho de 1783 fundaram o povoado. Fundada inicialmente por "dragões" 
comandados pelo tenente de Dragões Eusebio Vidal, juntamente com 46 famílias, que haviam sido destinadas originalmente a povoar a Patagonia, por parte da Coroa Espanhola. Juntamente com os dragões e estas famílias acompanharam 204 índios. Segundo o historiador Carlos Larriera a origem das famílias era: 43 asturianas, 05 castelhanas, 02 galegas, 01 andaluza e 01 de Astorga. Assim, semelhante a outras povoações como Minas e Rocha. Porém este projeto fracassou devido ao ambiente inóspito e os imigrantes foram redistribuídos na Banda Oriental (SAN JOSÉ - RESEÑA HISTÓRICA).

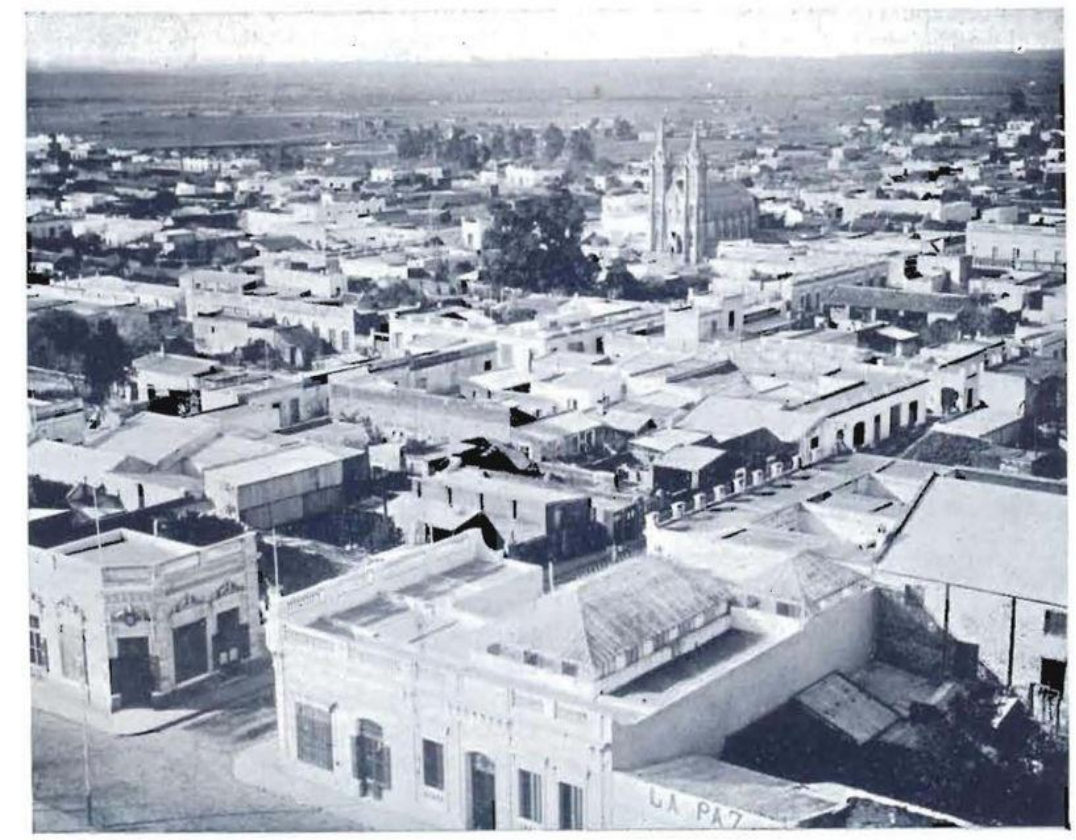

Figura 1 - Vista da cidade de San José em 1900.

Fonte: https://es.wikipedia.org/wiki/San_Jos\%C3\%A9_de_Mayo\#Ubicaci.C3.B3n Acessado em 19/10/2018

A cidade tem uma posição geográfica estratégica o que lhe outorgou um importante valor militar e político, pois se comunicava com Montevideo através dos povoamentos do litoral uruguaio - Mercedes, Paysandú, Salto e, inclusive, Colonia. Em 1807 a Vila foi ocupada pelos ingleses a mando do Cel. Denis Parker, que em 1815 participara da Batalha de Waterloo, chegando a ser capital da Província Cisplatina em 1822 (período que estava sob domínio português). Em 1856 foi elevada a categoria de cidade pela Lei 495 de 12/07/1856. Com o terminal ferroviário (1876), se viu expandir-se rapidamente seu comércio e indústrias, convertendo-se em uma das maiores cidades do interior do país. Contava a cidade com luz elétrica que era comandada por uma usina local. Também vai desde 1885 um importante hospital e em 1898 se havia erguido o primeiro monumento pátrio de José Artigas. A partir do final do século XIX e inicio do século XX se levou a cabo a construção de importantes obras, entre elas a inauguração em 1909 da ponte sobre o rio San José, em 1912 o luxuoso 
Teatro Bartolomé Macció e em 1913 se fundou o Liceo Departamental. O desenvolvimento de San José durante o século XX, quando o país desenvolve suas instituições democráticas e logra períodos de estabilidade política e econômica, está diretamente interligado ao desenvolvimento de suas indústrias. No departamento de San José está estabelecida a indústria leiteira (responde por $1 / 4$ da produção uruguaia) onde se inclui a Conaprole, Dolter AS, Frigorífico Modela, Granja Wallys, Mimencor AS, entre outras. A cidade de San José, capital do departamento, concentra boa parte desta indústria além da agropecuária, e segundo o censo de 2011 a cidade conta com uma população de 36.747 habitantes, de acordo com o Instituto Nacional de Estatísticas do Uruguai.

Jaguarão, no sul do Brasil e a nordeste de San José de Mayo, foi fundada em 1801 através de uma Guarda Militar portuguesa que em 1812 é elevada a Freguesia do Espírito Santo do Serrito de Jaguarão. Em 1832 é elevada a Vila de Jaguarão e no ano de 1855 a Município. Também possuía uma posição geográfica estratégica, ligada a Rio Grande/Pelotas pelo Canal de São Gonçalo e entrada para o Uruguai, através da Vila Virrey Arredondo (hoje Rio Branco).,

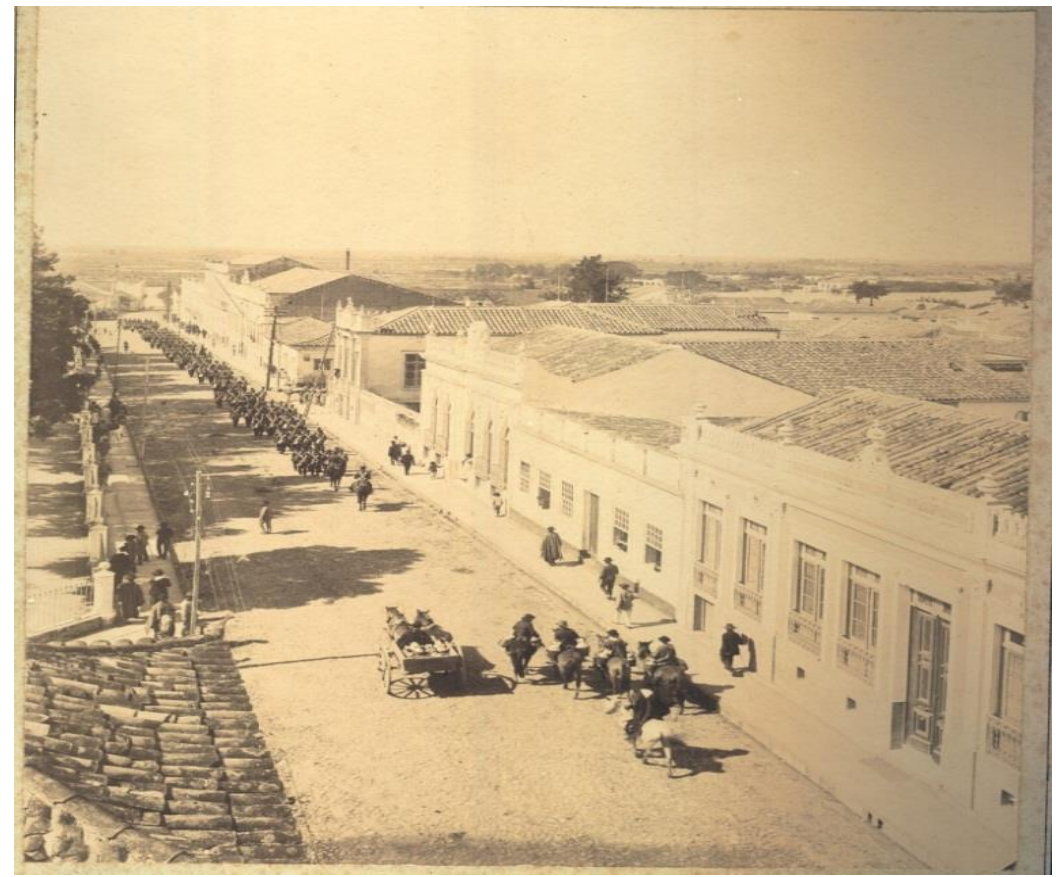

Figura 2 - Vista da cidade de Jaguarão no final do Séc. XIX.

Fonte: Arquivo do Instituto Histórico e Geográfico de Jaguarão

No final do século XIX se deu seu maior crescimento, tendo a cidade uma Usina Elétrica, um importante hospital, além de uma Enfermaria Militar, sendo o $5^{\circ}$ maior município do estado do RS em1879 (FRANCO, IN CADERNOS JAGUARENSES, 1990). 
No século XX a cidade de Jaguarão começa a sentir a queda de sua economia em função do fim do ciclo do charque e troca da principal rota de mercadorias para o Uruguai, transferindose para Bagé (Ferrovia). Manteve-se como uma cidade importante nas primeiras décadas, com a construção da Ponte Internacional Mauá e a presidência do Estado pelo jaguarense Carlos Barbosa. A partir da terceira década do século XX, a cidade continua a perder capital e prestígio político, tornando-se uma pequena cidade do interior, mas por outro lado, conservou-se quase intacto o patrimônio edificado. Seu desenvolvimento deve-se basicamente da agropecuária e do comércio, e nos últimos anos surge o turismo cultural em função das discussões em torno do Patrimônio, do tombamento estadual de quatro prédios em 1990 (MARTINS, 2002) e em 2011 do tombamento do Centro Histórico pelo IPHAN (Instituto do Patrimônio Histórico e Artístico Nacional).

\section{Das políticas públicas para o patrimônio}

No processo de reconhecimento do patrimônio, é possível demarcar duas etapas distintas: Antes e depois da criação da Organização das Nações Unidas. A primeira etapa compreendida entre 1877 e 1940, "período que se institucionaliza a preocupação pela conservação do legado histórico" (BÓLAN, 2010, p.17, tradução nossa), e na última década onde se discutem importantes acordos internacionais que definem condições e táticas para a preservação do patrimônio. O próximo período que vai da metade do século $\mathrm{XX}$ até nossos dias, "é quando se sistematizam internacionalmente as políticas de patrimônio" (Ibid., p.18).

A partir de 1972 com a Convenção da ONU (para proteção do patrimônio mundial, cultural e natural) e em 1975 com o ano europeu do patrimônio, onde a ideia de patrimônio integrado passa a fazer parte das políticas públicas para este setor, deslocando o paradigma da preservação para os da conservação e reabilitação. Nestes debates foram elencados alguns princípios da conservação integrada ${ }^{2}$ que vão servir de pilares para muitas políticas de memória e patrimônio em vários países, incluindo o Brasil e o Uruguai. Estes princípios são reforçados e recolhidos na Declaração de Amsterdã (1975), resultado do "Congresso sobre o Patrimônio Arquitetônico", que reuniu políticos e experts da Europa Ocidental e do Leste, dos Estados Unidos e Canadá, dos quais destacamos: o patrimônio é uma riqueza social, portanto,

\footnotetext{
${ }^{2}$ Sobre a questão da revitalização integrada, Oliveira \& Seibt nos assinala o seguinte: "O espaço urbano vem a ser um todo integrado pela aparência externa das edificações, pelos modos de construir, pelos usos, mas especialmente pelas normas de convivência [...]. É na possibilidade da integração dos tempos da cidade, nos encontros entre as gerações que se sucedem, que a memória torna-se um valor. É quando a revitalização pode começar, conforme Sylvio A. Dick Jantzen”. (OLIVEIRA, SEIBT, 2005, p.11)
} 
de responsabilidade coletiva; a conservação deve ser o objetivo principal da planificação urbana e territorial; a conservação integrada deve ser calcada em medidas legislativas e administrativas eficazes; existência de fundos públicos que apoiem as iniciativas das administrações locais; ser assunto de programas de educação, entre outras. (CASTRIOTA, 2010, p. 98).

Bolán (2010, p.30) nos apresenta um esquema elaborado por Ashworth (Universidade de Groningem, Holanda), que serve para ilustrar a evolução da interpretação sobre o tema do patrimônio dentro das políticas públicas e que apresentamos a seguir de forma adaptada:

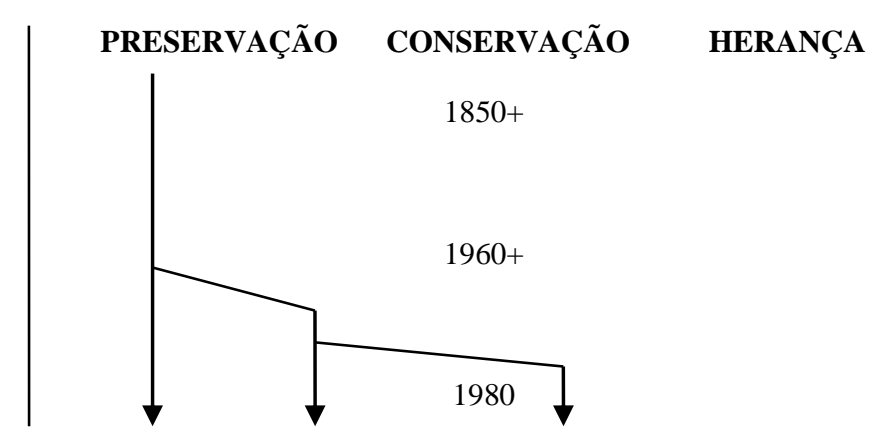

Figura 3 - Passos do processo evolutivo: do monumento histórico ao produto patrimonial Fonte: Bolán, 2010, p.30

O esquema apresentado buscava analisar o processo de mercantilização do patrimônio, assinalado por alguns autores, entre os quais, Ashworth. Aqui utilizamos no sentido mais didático, embora entendamos que o patrimônio alimenta o desenvolvimento das comunidades envolvidas, questão econômica, mas também envolve outras facetas como os aspectos políticos, sociais e afetivos, não podendo assim ser reduzido a uma questão meramente de mercantilização.

Na primeira década deste milênio amplia-se o debate sobre o patrimônio, incluindo o patrimônio cultural imaterial, levando a noção ampliada de patrimônio cultural, incluindo o material e o imaterial, ficando as citações apenas para recursos metodológicos. Em 2003 acontece a Convenção da ONU para a salvaguarda do Patrimônio Cultural Imaterial.

De acordo com Maria Cecília Londres Fonseca, "a constituição de patrimônios históricos e artísticos nacionais é uma prática característica dos Estados modernos" (1997, p. 21) e o discurso que costuma justificar a constituição desses patrimônios bem como o desenvolvimento de políticas públicas de preservação, busca valorar estes enquanto manifestações culturais e enquanto símbolos da nação. Assim, as políticas de preservação "se 
propõem atuar basicamente no nível simbólico, tendo como objetivo reforçar uma identidade coletiva, a educação e a formação de cidadãos". (Ibid., p. 21)

\subsection{No Brasil}

Dentro deste contexto da década de 1970, surge em 1975 o Programa de Cidades Históricas (PCH), que vem propor a reinserção de bens imóveis nas cidades como "elementos dinâmicos, e não mais estáticos, como eram tratados" (CASTRIOTA, 2010, p. 101). Os artigos 215 e 216 na CF/1988 vão consagrar dois princípios basilares: da Cidadania Cultural (o Estado garantirá a todos o pleno exercício dos direitos culturais e acesso às fontes da cultura nacional, e apoiará e incentivará a valorização e difusão das manifestações culturais). E da Diversidade Cultural (reconhece-se, assim, a pluralidade étnico-cultural de nossa formação histórica). Estas temáticas também são trabalhadas nos chamados PCN's, Parâmetros Curriculares Nacionais. Em 1995 vão acontecer tratativas entre Ministério da Cultura e BID (Banco Interamericano de Desenvolvimento) para um programa dessa natureza (Conservação Integrada). Em 2000 surge o Projeto Monumenta, que em 2003 ganha uma perspectiva diferente: Passa a estimular a contrapartida de estados e municípios e aumentar a sustentabilidade e capacidade de replicação. Buscou-se reaproximar o Programa do IPHAN, que havia sido relativamente afastado. Em 2005 passa a abranger também a Capacitação profissional, a Educação Patrimonial, apoio operacional, eventos culturais, promoção turística e publicações. Mais recentemente, em 2009, é apresentado pelo Governo Federal o "Programa de Aceleração do Crescimento (PAC) das Cidades Históricas" que em certa medida vai suceder o Monumenta. Voltado inicialmente para todos os municípios com sítios ou conjuntos urbanos tombados, ou em processo de tombamento pelo IPHAN, segue os princípios da Conservação Integrada. Dentro deste processo, Jaguarão é contemplada no PAC-Cidades históricas, e tem 11 projetos de restauração aprovados, entre eles o do Mercado Público Municipal, que foi o primeiro a ser licitado e já em processo de conclusão.

Os artigos escritos em língua portuguesa devem possuir também o título, o resumo $e$ as palavras-chave traduzidos para a língua inglesa e espanhola, como neste exemplo e os escritos em língua inglesa ou espanhola devem ter os itens citados traduzidos para o português e para a terceira língua faltante.

\subsection{No Uruguai}

Em 1971 é aprovada a Lei 14.040 que estabelece o conceito de patrimônio cultural e sua regulamentação. Em 2006 o Parlamento aprovou a Convenção da UNESCO 2003 (PCI), 
pela lei 18.035/2006, regendo a partir daí os governos departamentais e serviços correspondentes. Foram aprovadas algumas leis que criaram Fundos de financiamentos as atividades artísticas bem como o Fundo para o desenvolvimento de infraestruturas culturais no interior do país, através da Lei n 17.930 de 2005, que possibilitou verbas para recuperação de muitos bens patrimoniais. Este fundo, conforme o Site do Ministério de Educação e Cultura se encontra dentro das políticas culturais públicas desenvolvidas pelo Ministério de Educação e Cultura e estão a cargo da área de Cidadania e Território da Direção Nacional de Cultura (MEC). Através de chamadas públicas a projetos estes fundos tem como objetivo primordial melhorar as condições dos centros e espaços culturais públicos e/ou privados (salas, museus, bibliotecas, teatros e outros) do interior do país, mediante o financiamento de projetos, de reformas, adequação e melhoramentos, assim como equipamentos dos centros referidos e compra de imóveis.

Em 2009 aconteceram reuniões abordando a temática jurídica das diversas especificidades, impulsionado pela Comissão do Patrimônio Cultural da Nação (CPCN) e em 2011 foi realizado na cidade de La Paloma, a "Primeira Reunião de Expertos Jurídicos do Patrimônio Mundial para a América Latina e Caribe: reflexões sobre os aspectos jurídicos do patrimônio cultural nacional e sua relação com o Direito Internacional Público" (Quintela, in SOSA, 2013).

\section{Dos bens patrimoniais}

O Teatro Bartolomé Macció foi inaugurado em 05 de junho de 1912 com a presença do poeta Juan Zorrilla San Martín ${ }^{3}$ e um concerto dirigido por Luis Sambuceti ${ }^{4}$. Sua construção se deu após a morte do estancieiro Bartolomé Macció em 1900. Sua família, viúva e filhos, decidem fazer uma homenagem com a construção deste teatro.

Em 1956 quando o cinema estava em seu maior esplendor e a pouca atividade do teatro, o obrigou a fecha-lo, pois se encontrava em péssimas condições. Em 1959 os descendentes da família Macció vendem o edifício ao então, Banco San José, que o doa para a Intendência Municipal. A deterioração do edifício determinou que entre os anos de 1965 e 1973 ele passasse por obras de restauro, que o posicionaram como um dos mais ativos do país. Sob a direção do Arq. Oscar Ramos foi reinaugurado em 24 de agosto de 1973 e desde

\footnotetext{
${ }^{3}$ Juan Zorrilla de San Martín (Montevideo, 1855 - 1931). Escritor uruguaio representante principal da poesia romântica uruguaia.

${ }^{4}$ Arriba el télon!

http://ceibal.edu.uy/contenidos/areas_conocimiento/expresion/090319_dia_teatro/teatro_macci.html
} 
esta data vem mantendo atividades com obras locais, nacionais e internacionais, que o posicionam como um dos mais ativos do país.

Em 1984, o Ministério de Educação e Cultura o declara Monumento Histórico Nacional. Encontra-se no centro histórico da cidade de San José, no Uruguai, entre as ruas 18 de Julio e 25 de Maio. Tem capacidade para 700 espectadores distribuídos em um formato de ferradura, típico teatro de ópera a italiana. Destaca-se seu lustre de cristal de Murano e um telão de tecido italiano. Na sala Eduardo Carvajal se exibem obras plásticas de artistas nacionais e na sala Rafael Sienra se efetuam congressos, conferencias e diversas apresentações (SITE, CENTRO CEIBAL).

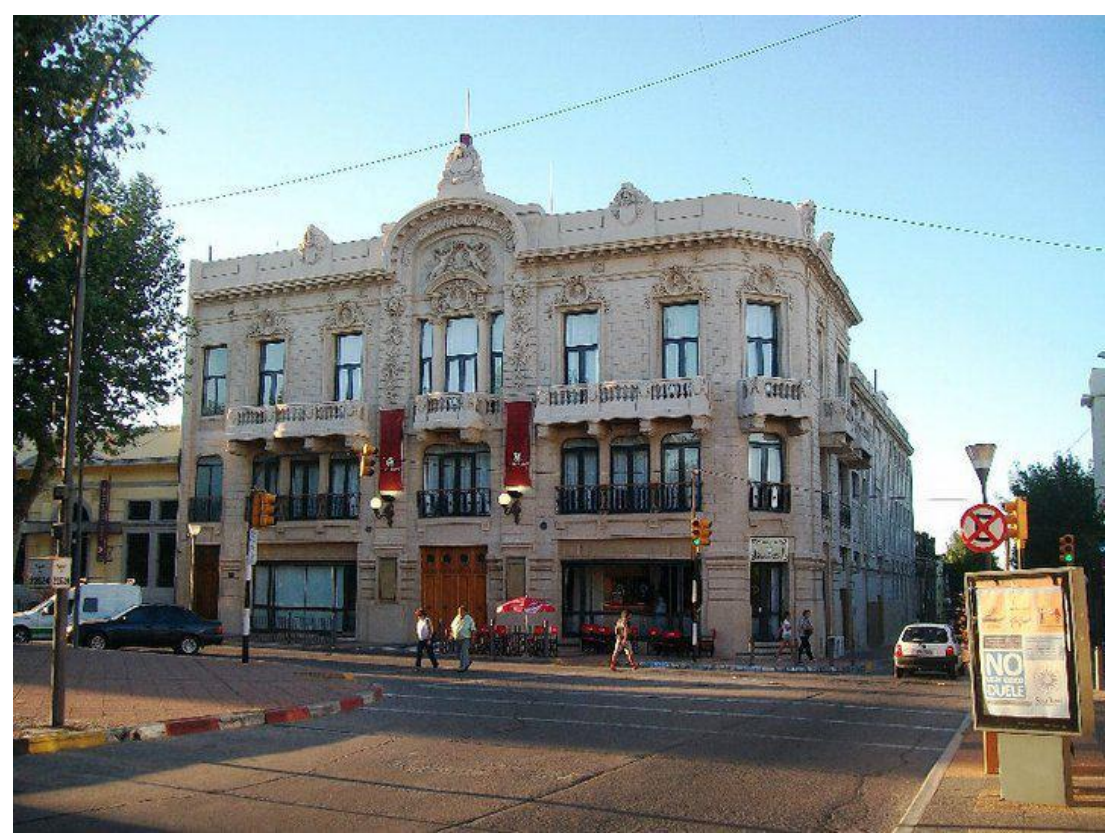

Figura 4 - Teatro Maccio: Foto de Diego Barboza

Fonte: https://commons.wikimedia.org/wiki/File:Teatro_Maccio.jpg\#/media/File:Teatro_Maccio.jpg Acessado em 19/10/2018

O Teatro Bartolomeu Macció na cidade de San José de Mayo (Uruguai) teve aprovado um projeto de restauração em 2009, do Escritório de Arquitetura Collet-Neri, liderado pelo arquiteto Diego Neri. O valor orçado foi de três milhões de dólares. Após o processo licitatório, a obra começou em maio de 2009, sendo reinaugurado em 13 de fevereiro de 2010. (VISION CIUDADANA, 01/04/2009).

Já o Mercado Público Municipal da cidade de Jaguarão (Brasil) data a sua construção do ano de 1864, sendo concluída totalmente a sua obra em julho de 1867. O prédio é de sólida construção feita em alvenaria, pertencente ao patrimônio do município, tendo passado por necessárias e importantes reformas, na administração do Coronel Frederico Rache (1920). 
Antigamente era cercado por grades, pois havia quartos neste local, ocupados por diversas bancas e açougue. Era um arrojado projeto para a época, século XIX, construído às margens do Rio Jaguarão, circundado por enormes figueiras - hoje centenárias. Esta construção colonial portuguesa atenderia a crescente população da cidade de Jaguarão, que estava em franco desenvolvimento naquele período. Em 1920 o prédio passou por uma grande intervenção onde "foram retiradas as grades que existiam sobre o muro e, provavelmente nesta mesma reforma, foi demolida uma das escadas de acesso ao prédio, [...] que já estava em ruínas" (Iphan, Dossiê de Tombamento, 2011).

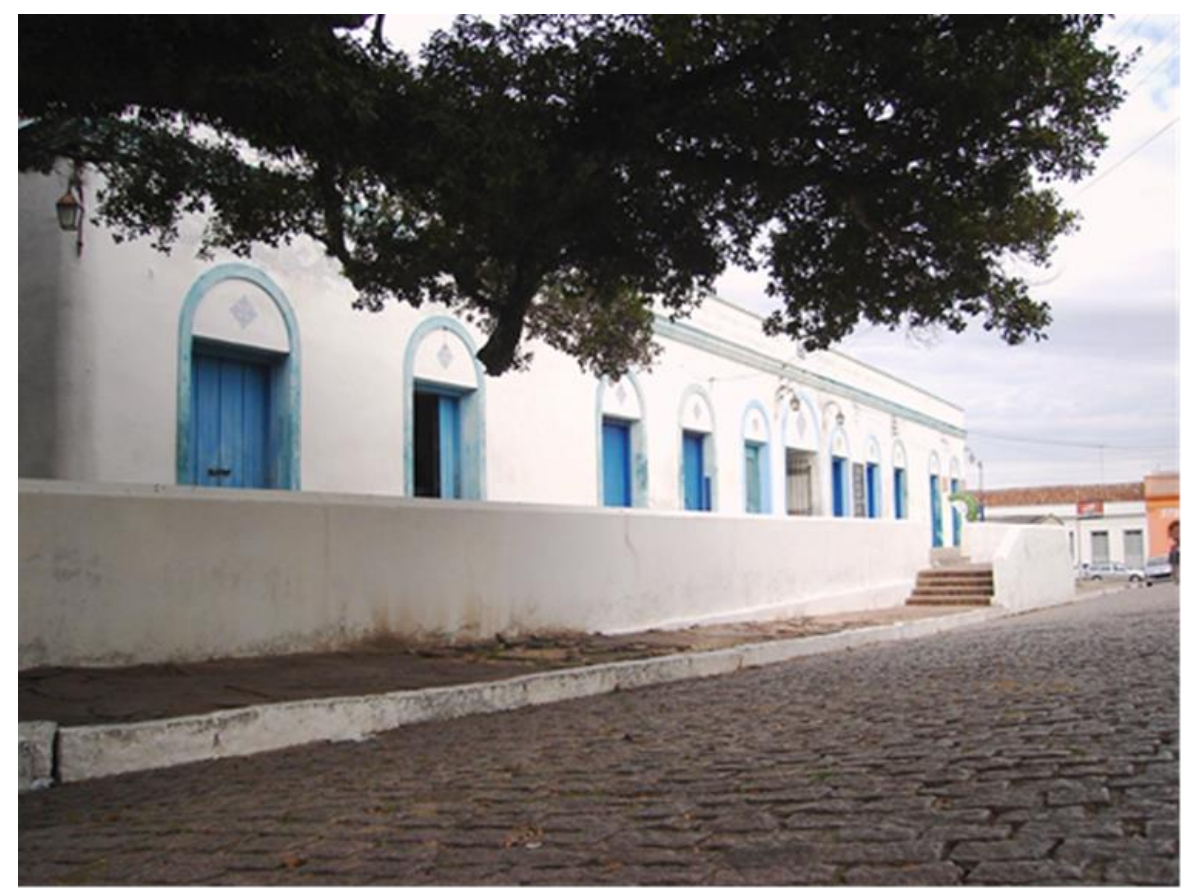

Figura 5 - Foto do Mercado Municipal de Jaguarão na década de 1990.

Fonte: Arquivo da Secult (Secretaria Municipal de Cultura e Turismo)

Funcionou ativamente até a década de 1970, onde a partir da década seguinte começa um processo de depreciação, terminando as feiras e permanecendo alguns usuários que passam a usufruir quase livremente do local, ocasionando vários estragos no prédio. $\mathrm{O}$ Mercado foi tombado pelo IPHAE/RS (Instituto do Patrimônio Histórico e Artístico do Estado do Rio Grande do Sul) em 1990 e pelo IPHAN em 2011, juntamente com o Centro Histórico. Recentemente teve aprovado um projeto de restauração no ano de 2012, assinado pelo arquiteto Marcelo Ferráz da empresa Brasil Arquitetura. O projeto foi aprovado no PACcidades históricas e o valor orçado em $\mathrm{R} \$ 4.499 .866,44$. A obra começou em julho de 2014 , a cargo da empresa Marsou Engenharia sendo a primeira do PAC, e a conclusão estava prevista para novembro de 2015. 
RELACult - Revista Latino-Americana de Estudos em Cultura e Sociedade

Revista Latinoamericana de Estudios en Cultura y Sociedad | Latin American Journal of Studies in Culture and Society V. 05, ed. especial, abr., 2019, artigo n ${ }^{\circ} 1166$ | claec.org/relacult |e-ISSN: 2525-7870

\subsection{Da restauração}

Em 2009 o intendente Juan Chiruchi contratou a empresa de Arquitetura Collet-Neri, por méritos, que realizou uma avaliação das instalações do teatro. O projeto incluiu a modernização de todas as instalações que necessitam um teatro no século XXI, respeitando o projeto original de princípios do século XX. Depois de contar com o projeto a Intendência Municipal chamou uma licitação a um custo de três milhões de dólares.

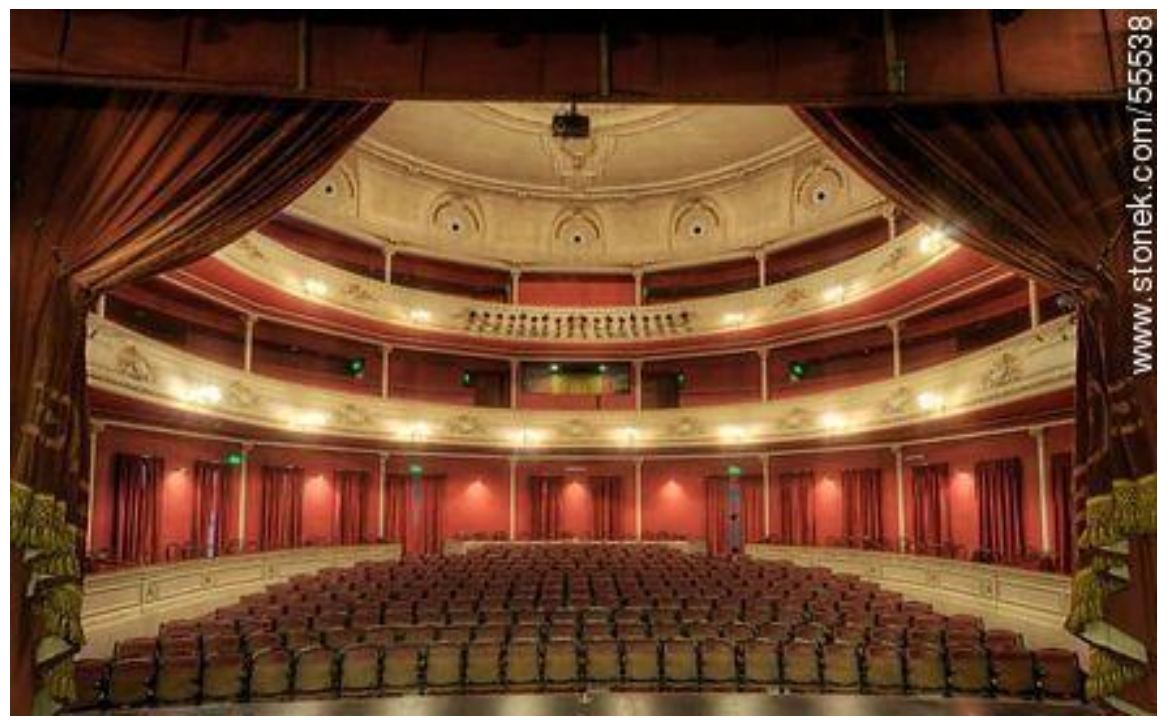

Figura 6 - Foto do Teatro Macció após a reinauguração.

Fonte: http://www.stonek.com/coment_es.php?outside=55538

Acessado em 01/12/2018

A edição digital do jornal Visión Ciudadana de 01 de abril de 2009 traz a seguinte matéria sobre a restauração:

Foi firmado na quarta-feira o contrato entre a Intendência de San José e Sabyl S.A. para dar inicio às obras de remodelação e readequação do Teatro Maccio. As mesmas terão um custo de cerca de três milhões de dólares, começaram na próxima segundafeira, dia 13 de abril e irão consumir um prazo aproximado de seis meses. $\mathrm{O}$ Intendente Juan Chiruchi disse no momento de firmar o documento que poucas vezes havia sendito "tanta responsabilidade e emoção". "Este é um ato merecido para a cultura do departamento e para este local em que recebera muitas figuras importantes. Nós entendemos que temos a responsabilidade de tratar a sua estrutura como uma maneira de se preparar para celebrar dentro de três anos, os 100 anos do o Teatro Maccio ", disse. O Arquiteto Diego Nery, autor do projeto que se executará, indicou que para sua realização "foram cuidadosamente analisados todos os aspectos e componentes de construção para reforçar e catapultar o teatro para o século XXI, fornecendo-lhe os mais recentes desenvolvimentos para permitir o melhor conforto, tanto para o público e para as equipes que usufruto". (tradução nossa)

O teatro foi reinaugurado em 13 de fevereiro de 2010 com a presença de autoridades nacionais e departamentais, assim como figuras destacadas na cultura nacional. A 
complexidade da declaração feita pelos arquitetos reside na manutenção cuidadosa da arquitetura original que contrastava com a instalação de vários serviços e instalações, não previstos inicialmente e agora necessários.

Em relação às obras podemos observar ainda na edição digital do jornal Visión Ciudadana de 01 de abril de 2009:

O Arquiteto Diego Freiría, membro da equipe estará a cargo das tarefas, deu detalhes gerais da mesma. Freiría informou que "o melhoramento e restauração do teatro inclui vários aspectos e, sem dúvida, um dos primeiros e mais importante é a melhoria da qualidade do património histórico que tem em suas fachadas e dentro do salão principal além do resto do edifício, o que tem uma importante degradação natural ao longo do tempo".

O profissional também disse que "não haverá grandes mudanças para a edificação. As escadas e salas de exposição do primeiro e segundo nível, que também será equipado para futuras exposições e eventos culturais "serão restaurados. Freiría disse que "um dos aspectos importantes é a incorporação de uma cafetaria, que será localizado onde hoje é o Escritório de Turismo". O arquiteto disse que haverá uma renovação total da área de administração do Teatro, e uma sala de linho também será adicionada. "A sala principal irá manter a sua qualidade ornamental e tipo de luzes, mas sera equipada com elementos como iluminação de palco e acústica. Ele também irá adicionar um novo mezanino na parte de trás do palco que irá acomodar novos camarins para moldes maiores", acrescentou. Finalmente, Freiría disse "ser incorporado facilidades para pessoas com deficiência, melhorando a acessibilidade com um elevador para aceder a qualquer nível de teatro e banheiros para facilitar o seu acesso". (tradução nossa)

Segundo os comentários em artigos, sobretudo na Revista Visión Ciudadana, e a análise do arquiteto responsável, observa-se uma cuidadosa restauração de componentes, observando os detalhes da arquitetura original. Houve a introdução de elementos modernos como o condicionamento do ar, sonorização, iluminação, porém buscou-se ao máximo manter estes aspectos de forma a não transformar a concepção do Teatro Clássico. Também foi restaurado o palco, com a sua remoção completa, para a construção de um novo que se esconde entre os vestiários, serviços, instalações e aparelhos de controle de acesso. Elétrica, dados, cuidados de saúde, iluminação e áudio foram completamente renovados.

Esta obra começou em abril de 2009 e foi concluída em fevereiro de 2010, portanto uma obra feita em 10 meses, com uma verba colocada pela Intendência de San José. Podemos inferir que foi um processo bastante rápido e eficiente, principalmente se compararmos com outras obras em instalações públicas. 


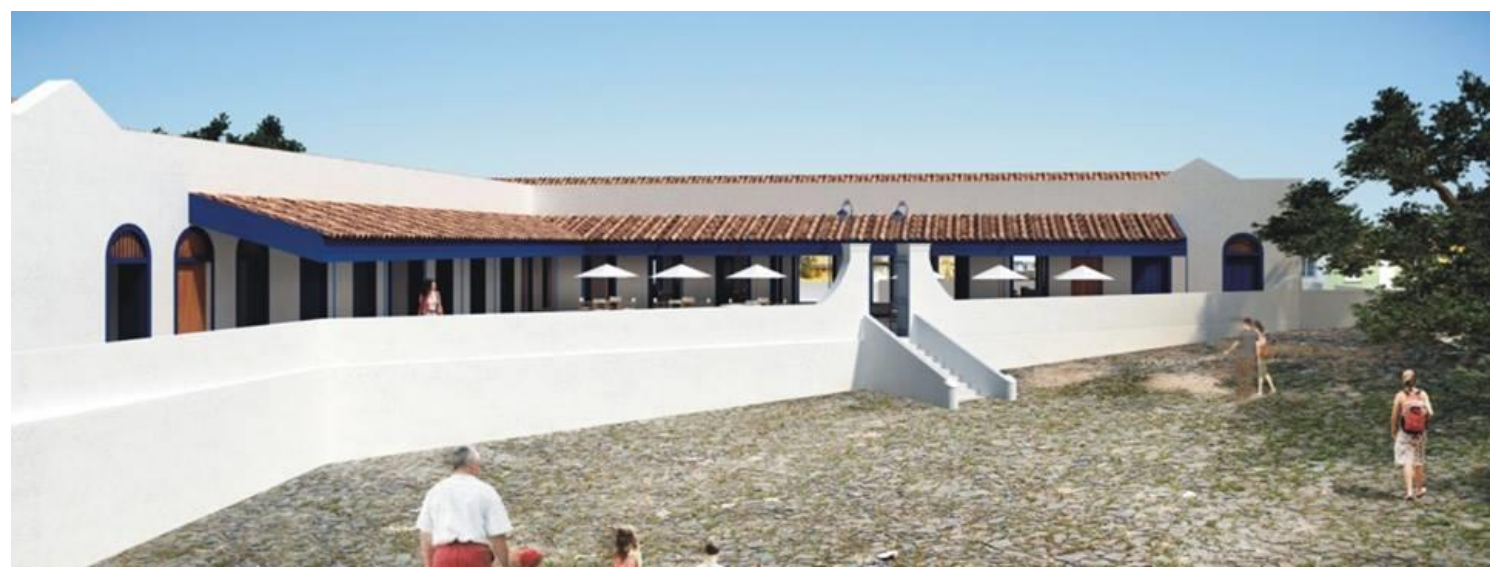

Figura 7 - Imagem do Projeto da Brasil Arquitetura. Parte interna do Mercado de Jaguarão. Fonte: http://www.jaguarao.rs.gov.br/?s=mercado+p\%C3\%BAblico Acessado em 19/10/2015

Em 2010 a Prefeitura Municipal de Jaguarão, através de uma verba adquirida via Governo do Estado, através do COREDE Sul (Conselho Regional de Desenvolvimento da Região Sul do estado do Rio Grande do Sul) e mais uma verba da própria prefeitura, resolve contratar um Projeto Técnico de Restauração do Mercado Público, que foi elaborado pela empresa Brasil Arquitetura, tendo como arquiteto Marcelo Ferráz. Com o PAC-Cidades Históricas (Plano de Aceleração de Crescimento do Governo Federal), Jaguarão teve 11 projetos aprovados que totalizarão 40 milhões de reais, entre eles o do Mercado Público Municipal. Já com o projeto pronto, foi o primeiro bem a começar a obra, tendo o contrato com a empresa vencedora para a execução, Marsou Engenharia, sido assinado em 14 de junho de 2014 (SITE, PMJ, 18/06/2014).

De acordo com o edital de licitação o prazo para a obra seria de 12 meses. A área total do Mercado é de $2.726 \mathrm{~m}^{2}$ e o orçamento previsto para o restauro é de $\mathrm{R} \$ 4.501 .804,74$ (quatro milhões, quinhentos e um mil, oitocentos e quatro reais e setenta e quatro centavos). Entre os serviços exigidos para o restauro do Mercado Público estão: estabilização estrutural do prédio; restauro da cobertura do prédio e varandas internas do pátio; restauro dos foros; restauro de rebocos e revestimentos; requalificação do prédio com a imunização e pintura em geral; execução de toda a infraestrutura necessária prevista no Projeto Arquitetônico e Executivo entre outros. Também foi realizado serviço de arte e plotagem dos tapumes da obra, para fins de divulgação e difusão do Patrimônio Cultural.

Em 2015 as obras de requalificação do prédio com a imunização e pintura em geral foram sendo realizadas, com a previsão de inauguração, de acordo com a empresa, para dezembro daquele ano, mas acabou entregue em 2017. Porém, até outubro de 2018 o município ainda 
não havia empreendido ação para que este espaço fosse utilizado pela comunidade, o que acarretou ações via Ministério Público para que o mesmo desse encaminhamento para garantir sua reinauguração e reintegração à vida do município. As últimas notícias antes de fechar este artigo, são de que o prefeito atual, Flávio Telis, enfim assinou o Decreto de Funcionamento do Mercado, no dia 06 de setembro de 2018, um ano após ter recebido o mesmo pela empresa executora.

\section{Considerações finais}

O processo de restauração do Teatro Macció em San José de Mayo e do Mercado Público Municipal de Jaguarão, inserem-se dentro do contexto de avanço nas políticas públicas para o patrimônio. A compreensão dos gestores públicos associado à capacidade técnica de suas equipes é que vai garantir maior ou menor avanço neste setor. O tempo de execução foi relativamente rápido, o que se compreende quando as verbas chegam de forma mais direta e o grupo gestor mais capacitado. Os recursos de ambos foram públicos e, por conta disto, espera-se um bom uso pela comunidade e que ambos possam ser polos incentivadores de cultura.

Trabalhando com alguns autores, Llorenç Prats (2005) considera Patrimônio primeiramente uma construção social, dialogando com a ideia da prática de memória obedecendo a um projeto de afirmação de si mesma em Joel Candau (2011). Pois para que determinados elementos se constituam como patrimônio têm de ser resgatados de um corpus cultural mais ou menos difuso e sujeitos a uma engenharia social que lhes confere valor e significado. Por conta desta "engenharia social" o Teatro Macció e o Mercado Público de Jaguarão se tornaram referenciais do patrimônio cultural, justificando as intervenções e investimentos públicos realizados. Mas sabemos que os bens restaurados e revitalizados não se tornam por si só garantia de que os mesmos manter-se-ão sempre ativos junto à cidade. A garantia de sua continuidade ativa passará pelo debate da gestão e uso deste bem. O envolvimento organizado da comunidade torna-se importante para que estas políticas deem certo. E um bom exemplo é a denúncia recebida pelo Ministério Público de Jaguarão contra o Município pelo fato de o mesmo não ter dado encaminhamento para a reinauguração do Mercado, tendo passado mais de 10 meses da obra executada. Como nos coloca Prats (2005) quando nos chama atenção para pensarmos a gestão patrimonial em conjunto (diretrizes), quesito onde se encontra a ideia de continuidade de uso e/ou preservação do bem tombado, e que é o que pode garantir o sentimento de pertencimento destas comunidades com o bem em questão, quesito fundamental para a manutenção destes como patrimônios culturais. 


\section{Referências}

BOLÁN, Eduardo. Del patrimonio como producto. La interpretación del patrimonio como espacio de intervención cultural. In: NIVEON, Eduardo, MANTECÓN, Ana Rosas (coords.) Gestionar el patrimonio en tiempos de globalización. México, Juan Pablo Editor, 2010.

FRANCO, S.C. In CADERNOS JAGUARENSES. Jaguarão: PMJ e IHGJ, v.1, 1990

CANDAU, Joel. Memória e Identidade. São Paulo, Contexto, 2011.

CASTRIOTA, Leonardo Barci. PAC Cidades Históricas - oportunidade para a conservação integrada? PDF. In: Locus, Revista de História, Juiz de Fora, V. 16, nº 2, p.93-117, 2010

CENTRO CEIBAL PARA EL APOUO A LA EDUCACIÓN DE LA NIÑEZ Y LA ADOLESCENCIA. Disponível em: http://www.ceibal.edu.uy/UserFiles/P0001/ODEA/ORIGINAL/090319_dia_teatro.elp/teatro_ macci.html Acessado em 09 de outubro de 2018.
FONDO PARA EL DESARROLLO DE INFRAESTRUCTURAS CULTURALES EM EL INTERIOR DEL PAIS. Disponível em: http://cultura.mec.gub.uy/innovaportal/v/13394/8/mecweb/fondo-para-el-desarrollo-de- infraestructuras-culturales-en-el-interior-del-pais?leftmenuid=13394 Acessado em 09/10/2018

FONSECA, Maria Cecília Londres. O patrimônio em processo: trajetória da política federal de preservação no Brasil. Rio de Janeiro: UFRJ/IPHAN, 1997.

INSTITUTO NACIONAL DE ESTATÍSTICA (Uruguai). Disponível em: http://www3.ine.gub.uy:82/anda4/index.php/catalog/243/export\#page=dataappraisal

Acessado em 09/12/2018

INSTITUTO DO PATRIMÔNIO HISTÓRICO E NACIONAL (IPHAN). Dossiê de Tombamento do Conjunto Arquitetônico e Paisagístico de Jaguarão. Porto Alegre: Ministério da Cultura; IPHAN, 2010.

MARTINS, Roberto Duarte. A ocupação do espaço na fronteira Brasil-Uruguai: a construção da cidade de Jaguarão. Tese. (Doutorado em Histórias Especializadas) Universidade Politécnica da Catalunha, 2002.

PRATS, Llorenç. Concepto y gestión del patrimonio local. Cuadernos de Antropología Social No21, pp. 17-35, 2005. Pdf

PREFEITURA MUNICIPAL DE JAGUARÃO. Disponível em:

http://www.jaguarao.rs.gov.br/ Acessado em 08 de outubro de 2015.Notícias: 18/06/2014

QUINTELA, Alberto. La institucionalidad del patrimonio cultural en Uruguay. In: SOSA, Ana M. G.; FERREIRA, Maria Leticia M. \& REY ASHFIELD, William. Patrimônio cultural: Brasil e Uruguai: os processos de patrimonialização e suas experiências. Pelotas: Ed. da Universidade Federal de Pelotas, 2013. - 243p.

SAN JOSÉ - RESENHA HISTÓRICA. Disponível em: http://www.tacuy.com.uy/Servicios/San\%20Jose/index.htm Acessado em 08 de outubro de 2018. 
Visión Ciudadana - Edição digital. Disponível em: http://www.visionciudadana.com.uy/ Acessado em 08 de outubro de 2018. Notícias: 01/04/2009; 04/11/2009; 10, 13 e 14 de fevereiro de 2010. 